\title{
Article
}

\section{Genotype-Environment Correlation and Its Relation to Personality — A Twin and Family Study}

\author{
Bertil Persson \\ Department of Psychology, Lund University, Lund, Sweden
}

\begin{abstract}
The aim of the study was to examine the Family and School Psychosocial Environment (FSPE) questionnaire in relation to a possible genotype-environment correlation and genetic mediation between the FSPE variables and personality variables, assessed by the Junior Eysenck Personality Questionnaire. A sample of 506 Swedish children aged 10-20 years from 253 families were recruited via the Swedish state population and address register and SchoolList.Eu. The children were divided into 253 pairs: 46 monozygotic twin pairs, 42 dizygotic twin pairs, 140 pairs of full siblings and 25 pairs of half-siblings. The behavioral genetic analysis showed that both FSPE factors, Warmth and Conflicts, may be partly influenced by genetic factors (suggesting genotype-environment correlation) and that nonadditive genetic factors may mediate the relationship between FSPE factors and psychoticism/antisocial personality (P). An indication of a special shared monozygotic twin environment was found for $\mathrm{P}$ and Lie/social desirability, but based on prior research findings this factor may have a minor influence on $\mathrm{P}$ and L. P and L were negatively correlated, and the relationship seems to be partly mediated by nonadditive genetic factors. Nonshared environment and measurement errors seem to be the most influential mediating factors, but none of the cross-twin cross-dimension correlations suggest a common shared environmental mediating factor.
\end{abstract}

Keywords: Genotype-environment correlation; genetic mediation; psychosocial environmental measure; personality

(Received 31 March 2020; accepted 23 June 2020; First Published online 10 August 2020)

Behavioral genetic research has shown that psychosocial environmental measures are important tools in the study of personality and also that such measures may be influenced by genetic factors that relate to personality. Genotype-environment correlation $(r \mathrm{GE})$ and genetic mediation $(\mathrm{Gm})$ are two closely related concepts that have gained increasing interest in recent decades. $r$ GE implies that genes affect environments indirectly via personality characteristics. Two $r$ GE-types are of special interest in the field of personality research: reactive (or evocative) $r \mathrm{GE}$ refers to responses that are evoked from the environment by genetically influenced behaviors. Active $r$ GE refers to instances where individuals themselves select their environment based on their genetic predispositions. In both cases, a correlation between environment and personality will occur for genetic reasons (Gm) (Jaffee \& Price, 2007; Plomin, 2014).

The authors of a meta-analysis based on 32 twins-rearedtogether studies concluded that the research on $r \mathrm{GE}$ is in its infancy and more studies on a variety of environmental measures are needed (Avinun \& Knafo, 2014). In their study, an average heritability of $23 \%$ was found for family environmental measures, $43 \%$ was related to shared environment and $34 \%$ was related to nonshared environment. Kendler and Baker (2007) found similar results in a meta-analysis that also included twin studies. Vinkhuyzen et al. (2010) found an average heritability of $49 \%$

Author for correspondence: Bertil Persson, Email: Bertil.Persson@Psy.Lu.Se Cite this article: Persson B. (2020) Genotype-Environment Correlation and Its Relation to Personality - A Twin and Family Study. Twin Research and Human Genetics 23: 228-234, https://doi.org/10.1017/thg.2020.63 based on four different environmental measures, and a recent large twin study showed genetic influences on parenting (Warmth and Stress) mediated by genetically influenced personality (especially agreeableness and conscientiousness; Ayoub et al., 2019). Studies of $r \mathrm{GE}$ on twins reared apart are rare, but one large Swedish study, based on both twins reared apart and together, showed a similar heritability (26\%) for perceived parenting when measured using the Family Environment Scale (Plomin et al., 1988). Recently, $r \mathrm{GE}$ was tested in a genomewide molecular genetic study on family environment, which showed heritabilities between $2 \%$ and $23 \%$ (Dobewall et al., 2019).

Compared to the vast array of personality tests available, fewer psychometrically validated environmental measures have been produced. In a recent study, family and school psychosocial environment (FSPE) was tested on 244 Swedish children where FSPE covered both current familial and extrafamilial (school) environmental factors (Persson, 2011). The FSPE factors, Warmth, Support and Openness from Parents (FSPE1) and Family Conflicts and School Discipline (FSPE2), were shown to correlate with Eysenck's personality factors (Persson, 2014). The highest correlations (.47) were found between FSPE2 and psychoticism (antisocial personality) and between FSPE1 and extraversion (.28). These correlations may, however, be influenced by genetic factors, and the author suggested that they be tested for $r$ GE (Persson, 2014). $\mathrm{Gm}$ has been found for personality-environment relationships in several studies (Chipuer et al., 1993; Klahr et al., 2013) but was not supported in other studies (Vernon et al., 1997). In a recent review, Plomin et al. (2014) highlighted the significance of both $r \mathrm{GE}$ and Gm.

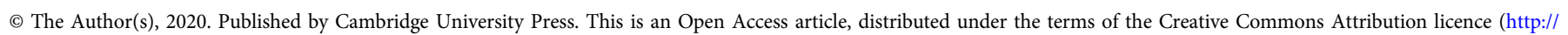
creativecommons.org/licenses/by/4.0/), which permits unrestricted re-use, distribution, and reproduction in any medium, provided the original work is properly cited. 
In order to analyze $r \mathrm{GE}$ and $\mathrm{Gm}$, a genetically sensitive design must be applied. Such a design includes twin and/or sibling pairs with varied genetic relatedness. The goal of the present study was to unravel possible $r \mathrm{GE}$ related to warmth and conflicts and to determine whether $\mathrm{Gm}$ factors can explain correlations between these factors and personality.

\section{Materials and Methods}

\section{Participants}

The Swedish State Population and Address Register (SPAR) is a population-based register with addresses of all families in Sweden. An enquiry was sent to 2000 families in addition to teachers at 50 schools that were randomly contacted via SchoolList.Eu. The recipients (a parent or teacher) received a form asking whether there were twins, full siblings (FSs) or half-siblings (HSs) aged $10-20$ years in the family or school who are willing to participate. Responses were received from 271 families. Information regarding twin zygosity and sibling type was provided by the participants' parents. If the family consisted of more than two children, the closest in age were chosen. Parents who could not provide information about twin and sibling type and/or did not follow the provided test instructions were excluded. After exclusion, the sample consisted of 506 participants, divided into 46 pairs of monozygotic (MZ) twins, 42 pairs of dizygotic (DZ) twins, 140 pairs of FSs and 25 pairs of HSs; same-sex pairs: MZ 46, DZ 18, FS 77 and HS $14)$. The mean age was 15.0 years for the $M Z$ twins $(S D=3)$, 15.0 years for the $\mathrm{DZ}$ twins $(S D=3), 13.8$ years for FS $(S D=2.5)$ and 15.5 years for HS $(S D=3.5)$. More females than males participated in the MZ, DZ and HS groups $(73.9 \%, 61.4 \%$ and $61.4 \%$, respectively). In the FS group, $49.1 \%$ were female. The mean number of siblings within the families was: MZ $2.4(S D=1.0)$, DZ 2.2 $(S D=1.3)$, FS $1.9(S D=1.2)$ and HS $2.9(S D=1.5)$. According to Statistics Sweden (2019), the mean number of children within families is 1.8 . However, families with no children or only one child were not addressed, which explains the somewhat higher figures in the present study.

\section{Materials}

FSPE. The FSPE is a Swedish factor analyzed and cross-validated environmental measure (Persson, 2011), originally based on an interview related to the psychosocial growth environment for migraine discordant siblings (Persson, 1997). The 26 items in the FSPE cover subject-parent, subject-sibling, subject-teacher and subject-peer relations, and events in those relations. The form comprises two higher order factors: FSPE1: Warmth, Support and Openness from Parents, Siblings and Peers (shortened to Warmth; example items are: 'My parents hug me,' 'My parents take me to different places when I need it,' 'My parents and I have fun together,' 'My parents help me with homework,' 'Siblings say they like me' and 'I get invited to my pals' parties'; Cronbach's $\alpha=.82$ ); FSPE2: Family Conflicts and School Discipline (shortened to Conflicts; example items are: 'My parents yell at each other,' 'My parents spank me,' 'Siblings tease me and hit me,' 'Teachers send complaints to my parents,' 'Teachers banish me from the classroom' and 'Teachers retain me in school after class'; Cronbach's $\alpha=.71$ ). The items are answered on a 4-point Likert scale: $0=$ Never, $1=$ Sometimes, $2=$ Often, $3=$ Very often.

The Junior Eysenck Personality Questionnaire (J-EPQ). The $J$-EPQ is a well-validated personality test that consists of three personality scales. It has been standardized on a Swedish population
(Eysenck et al., 1988). The form comprises four secondary factors: Extraversion (E) with 24 items that relate to impulsivity and sociability (example items are: 'Do you like exciting things to happen?,' 'Do you have many friends?,' 'Do you like to tell jokes to your friends?'; Cronbach's $\alpha=.73$ ); Neuroticism (N) with 22 items that relate to traits such as nervousness and sensibility (example items are: 'Do you often feel that life is boring?,' 'Are you usually worried that terrible things will happen?,' 'Do you often have nightmares?'; Cronbach's $\alpha=.84$ ); psychoticism (P) with 21 items that relate to unfriendliness and coldness (example items are: 'Do you sometimes like to see when a gang mob younger kids?,' 'Do you want to hurt people you actually like?,' 'Do you wish other children being afraid of you?'; Cronbach's $\alpha=.64)$. The P-scale correlates negatively with the Big Five personality trait Agreeableness (A) (Colledani et al., 2018; Costa \& McCrae, 1985). Since the concept psychoticism leads to confusion, the concept will be supplemented and called psychoticism/antisocial personality in this article. Psychoticism does not correlate with psychotic behavior, but to antisocial personality behavior (Chapman et al., 1993; Heath \& Martin, 1990; Wakefield, 1997); Lie (L) is intended to be a validation scale, but some researchers, including Eysenck himself (Eysenck \& Eysenck, 1976), postulate that this scale may relate to personality. Indeed, agreeableness (A) and conscientiousness (C) correlate positively with L (Brajsa-Zganec et al., 2011; Ones et al., 1996) and L correlates negatively with P (Roy, 2012; Persson 2014). Further, people high on P lie more often to themselves and others, but high A relates to low scores for deception (Sarzynska et al., 2017). The negative correlation between P and $\mathrm{L}$ indicates that people high on $\mathrm{P}$ do not strive for social desirability (i.e. they possess low L). For these reasons, the L-scale will be considered a personality factor and designated lie/social desirability. The L-scale consists of 22 items (Cronbach's $\alpha=.78$ ). Example items are: 'Do you always obey when you are told?,' 'Have you ever cheated in a game or play?,' and 'Have you ever stolen something?'

\section{Procedure}

A test envelope was sent to the participant's parent, who acted as test leader. The test leader followed written instructions given by the author. The FSPE and J-EPQ forms were answered by the children simultaneously but in different rooms. Only age, sex and number of siblings were added on the form. The participant placed the forms in a sealed envelope, which was handed over to the test leader. A form about zygosity and type of siblings was answered by the test leader. All materials were then placed in a larger envelope addressed to the author.

\section{Statistical Analysis}

Personality differences for E, N, P, L and differences on FSPEWarmth and FSPE-Conflicts between MZ, DZ, FS and HS groups were tested using an analysis of variance with a post hoc test for multiple comparisons. Phenotypic intercorrelations were calculated with Pearson's $r$ based on the participants absolute scores $(N=506)$.

A behavioral genetic analysis was done by computing intraclass correlation $(R)$ for the FSPE factors in order to identify $r \mathrm{GE}$, and for the J-EPQ personality factors, in order to estimate the contribution of genetic and environmental factors. Heritability was estimated by two different approaches, depending on the pattern of Rs obtained for the MZ and DZ twins (and additional information based on the $R \mathrm{~s}$ in the FS and HS groups). If the $R_{\mathrm{DZ}}$ was higher than half the $R_{\mathrm{MZ}}$, the formula suggested by Falconer and 
Table 1. Descriptive statistics for the full sample and for MZs, DZs, FSs and HSs, respectively (means and standard deviation within brackets)

\begin{tabular}{lcccccccccc}
\hline & Sex F/M\% & Age & NumSib & E & N & P & L & FSPE1-Warmth & FSPE2-Conflicts \\
\hline MZ $(n=92)$ & $73.9 / 26.1$ & $15.0(2.9)$ & $2.3(1.0)$ & $16.0(4.3)$ & $9.6(5.7)$ & $1.8(1.9)$ & $9.9 n(4.2)$ & $27.7(6.2)$ & $4.3(2.2)$ \\
\hline DZ $(n=84)$ & $61.4 / 38.6$ & $15.0(3.1)$ & $2.2(1.3)$ & $16.9(4.2)$ & $9.5(5.0)$ & $2.9(2.6)$ & $9.2(3.7)$ & $27.3(6.7)$ & $4.7(2.3)$ \\
\hline FS $(n=280)$ & $49.1 / 50.9$ & $13.8(2.4)$ & $1.9(1.2)$ & $17.4(4.0)$ & $8.9(4.9)$ & $3.3(2.8)$ & $8.2(4.0)$ & $26.1(6.0)$ & $5.1(2.6)$ \\
\hline HS $(n=50)$ & $60.4 / 39.6$ & $15.5(3.6)$ & $1.5(1.5)$ & $17.1(3.5)$ & $11(5.8)$ & $3.6(2.7)$ & $8.3(4.5)$ & $25.7(6.2)$ & $5.1(2.8)$ & $4.9(2.5)$ \\
\hline All $(N=506)$ & $61.2 / 38.8$ & $14.4(2.9)$ & $2.2(1.2)$ & $17.0(4.1)$ & $9.3(5.2)$ & $2.9(2.6)$ & $8.7(4.1)$ & $26.5(6.2)$ & $4.2)$ \\
\hline
\end{tabular}

Note: E, extraversion; N, neuroticism; P, psychoticism/antisocial personality; L, lie/social desirability; FSPE1-Warmth, Warmth, support and openness from parents, siblings and peers; FSPE2-Conflicts, Family conflicts and school discipline; NumSib, number of siblings.

Table 2 Phenotypic intercorrelations between the variables in the full sample $(N=506)$

\begin{tabular}{|c|c|c|c|c|c|c|c|c|}
\hline & 1 & 2 & 3 & 4 & 5 & 6 & 7 & 8 \\
\hline 2. $\mathrm{N}$ & $-.12 * *$ & & & & & & & \\
\hline 4. $\mathrm{L}$ & $-.10 *$ & $-.18 * * *$ & $-.49 * * *$ & & & & & \\
\hline 5. FSPE1-Warmth & $.21^{* * * *}$ & -.05 & $-.27 * * *$ & $.13 * *$ & & & & \\
\hline 7. Age & $-.16^{* * *}$ & $.15^{* * *}$ & $.19 * * *$ & $-.22 * * *$ & -.03 & $-.14 * *$ & & \\
\hline 8. Sex & $-.10 *$ & $.20 * * *$ & $-.28 * * *$ & .07 & $.20 * * *$ & $-.11 *$ & $.13^{* *}$ & \\
\hline 9. NumSib & -.02 & $.11^{* *}$ & $.10 *$ & -.01 & -.13 & -.01 & $.14 * * *$ & 0 \\
\hline
\end{tabular}

Note: E, extraversion; N, neuroticism; P, psychoticism/antisocial personality; L, lie/social desirability; FSPE1-Warmth, Warmth, support and openness from parents, siblings and peers; FSPE2-Conflicts, Family conflicts and school discipline; NumSib, number of siblings. Sex: $1=$ Female, $0=$ Male.

${ }^{\star} p \leq .05,{ }^{\star \star} p \leq .01,{ }^{\star \star \star} p \leq .001$.

Mackay (1998) was used: $2\left(R_{\mathrm{MZ}}-R_{\mathrm{DZ}}\right)$. The $R$ pattern suggests a primarily additive genetic influence (narrow-sense heritability, $h^{2}{ }_{\mathrm{a}}$ ). However, if $R_{\mathrm{MZA}}>2 R_{\mathrm{DZ}}$, that is, the $R_{\mathrm{DZ}}$ is substantially lower than half the $R_{\mathrm{MZ}}$, the $h^{2}$ will be inflated. In these cases, an approach suggested by Loehlin (1972) and Vukasovic and Bratko (2015) was applied: $h^{2}=R_{\mathrm{MZ}}$ (i.e. broad-sense heritability, $h_{\mathrm{b}}^{2}$ ), assuming the absence of shared environment. The $R$ pattern suggests that nonadditive genetic influence may be important, provided that the equal environment assumption (EEA) is valid. $h^{2}$ includes, in addition to additive genetic variance, genetic dominance and three types of epistasis (Cheverud \& Routman, 1996; Keller et.al, 2005).

Shared environment $\left(c^{2}\right)$ was estimated by $R_{\mathrm{MZ}}-h^{2}$ and nonshared environment $\left(e^{2}\right)$ by $1-R_{\mathrm{MZ}}$. If the EEA is not valid, the $c^{2}$ will be underestimated and $h^{2}$ will be overestimated. If the reliability of the measures is not 1 , the $e^{2}$ will be overestimated.

Finally, in order to study Gm, cross-twin, cross-dimension correlation was calculated for each significant correlation between the FSPE environmental factors and J-EPQ personality factors (and between factors in each test).

Cross-twin, cross-dimension correlation $\left({ }_{\text {cross }} r\right)$ can be computed in two ways: from twin 1 to twin 2 or from twin 2 to twin 1 . However, the average cross $r$ of the two correlations will represent a more reliable estimate. Environmental scores for twin 1 are correlated with personality scores for twin 2, and vice versa, then averaging the correlations. The same was done for pairs of FS and HS.

If the ${ }_{\text {cross }} r$ is higher for MZ twins than DZ twins, Gm is suggested. If $\mathrm{DZ}_{\text {cross }} r$ is substantially greater than half the $\mathrm{MZ}_{\text {cross }} \mathrm{r}$, shared environment mediation is suggested. If the $M Z$ and
$\mathrm{DZ}_{\text {cross }} r$ are close to zero (or insignificant), nonshared environment mediation is suggested.

\section{Results}

Mean scores and standard deviations for the full sample and for MZ, DZ, FS and HS, respectively, are presented in Table 1. Means and standard deviations were quite similar for most of the variables and groups, but some differences were significant. For psychoticism/antisocial personality (P), MZ scores were 1.5 points lower than FS and HS. For lie/social desirability (L), MZ scores approximately 1.5 points lower than FS. MZ and DZ twins were on average 1 year older than FS, and FSs were about 1 year younger than HS. HS had, on average, one sibling more than FS but about one sibling less than MZ. Cohen's $d$ ranged from 0.4 for the MZ-FS difference on L and 0.75 for the MZ-HS difference on $\mathrm{P}$.

Several phenotypic correlations were identified (see Table 2). The highest correlations were found between $\mathrm{P}$ and $\mathrm{L}$ - sharing $24 \%$ of the variance (negative correlation), and between $\mathrm{P}$ and Conflicts - sharing $16 \%$ of the variance (positive correlation). $\mathrm{P}$ correlated negatively with Warmth, age and sex, sharing $3.6 \%-7.8 \%$ of the variance. $\mathrm{L}$ was negatively correlated with Conflicts (sharing $14.4 \%$ of the variance), E positively related to Warmth (sharing $4.4 \%$ of the variance), and $\mathrm{N}$ was positively related to sex and $\mathrm{P}$ (sharing $4 \%-6.2 \%$ of the variance). Warmth and Conflicts were negatively correlated.

Intraclass correlations for the personality variables and environmental measures are presented in Table 3. Correlations 
Table 3. Intraclass correlations (R) for 46 pairs of MZ, 42 pairs of DZ twins, 137 pairs of full siblings (FS) and 25 pairs of half siblings (HS), respectively, and estimates of heritability and environmental influences based on the twin correlations (95\% confidence intervals in brackets)

\begin{tabular}{|c|c|c|c|c|c|c|c|c|}
\hline Variable & $\mathrm{RMZ}$ & $\mathrm{RDZ}$ & RFS & RHS & $h^{2}{ }_{\mathrm{a}}$ & $h_{\mathrm{b}}^{2}$ & $c^{2}$ & $e^{2}{ }_{c}$ \\
\hline $\mathrm{E}$ & $.394 * *(.122, .611)$ & $.315^{*}(.018, .561)$ & $.208 * *(.042, .362)$ & $-.199(-.541, .203)$ & .16 & & .23 & .61 \\
\hline $\mathrm{N}$ & $.551 * * *(.316, .724)$ & $.544 * * *(.293, .726)$ & $.318 * * *(.160, .460)$ & $.352 *(-.036, .650)$ & .01 & & .54 & .45 \\
\hline $\mathrm{P}$ & $.628 * * *(.418, .775)$ & $-.077(-.367, .228)$ & $.103(-.065, .265)$ & $.046(-0.343, .424)$ & & .63 & 0 & .37 \\
\hline L & $.754 * * *(.597, .856)$ & $.057(-.246, .351)$ & $.202(.037, .357)$ & $-.002(-.384, .385)$ & & .75 & 0 & .25 \\
\hline FSPE1-Warmth & $.715 * * *(.540, .831)$ & $.475^{* * *}(.206, .678)$ & $.358 * * *(.203, .495)$ & $.253(-.144, .582)$ & .24 & & .48 & .28 \\
\hline FSPE2-Conflicts & $.549 * * *(.313, .722)$ & $.249(-.054, .510)$ & $.196 *(.030, .352)$ & $.458 * *(.091, .717)$ & & .55 & 0 & .45 \\
\hline
\end{tabular}

Note: E, extraversion; N, neuroticism; P, psychoticism/antisocial personality; L, lie/social desirability; FSPE1-Warmth, Warmth, support and openness from parents, siblings and peers; FSPE2-Conflicts, Family conflicts and school discipline; $h^{2}$ a narrow-sense heritability; $h^{2}$ b broad-sense heritability; $c^{2}$, shared environment; $e^{2}$, nonshared environment $l_{c}$, includes error of measurement).

${ }^{\star} p \leq .05,{ }^{\star \star} p \leq .01,{ }^{\star \star \star} p \leq .001$

for the DZ-pooled group of same and opposite sex $(n=42)$ did not differ significantly from the DZ same-sex group $(n=18)$. A control partial correlation analysis based on the full sample showed that none of the phenotypic intercorrelations were altered when the effect of sex was removed. Thus, in order to increase power, the results in the larger sample are presented. For P, the pattern of correlations suggests nonadditive genetic influences, as the $\mathrm{MZ}$ correlation is substantially greater than double the DZ correlation. As for DZ twins, the correlations for FS and HS are also low, which further supports a nonadditive genetic hypothesis. The same pattern was found for L. For these two traits, substantial broad-sense heritability is suggested. Nonshared environment (measurement error included) explains some of the variance, but a common shared environment was not detectable for $\mathrm{P}$ and $\mathrm{L}$.

The pattern of correlations for E suggests narrow-sense heritability, as the MZ twin correlation is less than double the DZ twin correlation. Shared environment explains approximately as much as the genetic factors. However, nonshared environment and measurement error account for a majority of the variance seen on $\mathrm{E}$.

Significant correlations were found for $N$ in all four groups, but the differences between MZ and DZ and between FS and HS were nonsignificant, suggesting low heritability and substantial shared and nonshared environment.

$r$ GE implies that genetic factors account for differences in the perceived psychosocial environment (see Table 3). A higher correlation for $\mathrm{MZ}$ compared to $\mathrm{DZ}$ suggests narrow-sense heritability for Warmth, as the MZ correlation is not greater than double the DZ correlation. Genetic factors account for approximately onefourth of the variance. Most of the variance is related to shared environment and some to nonshared environment, as the MZ correlation is less than 1 .

The pattern of correlations for Conflicts is not as clear as for Warmth. The MZ correlation is more than double the DZ correlation, and the DZ correlation is not significant. This supports a nonadditive genetic hypothesis. On the other hand, the FS and HS correlations are significant, suggesting that additive genetic effect or shared environment has some effect. Nonshared environment is unambiguously related to Conflicts, as the MZ correlation is substantially lower than one and the MZ-difference scores on Conflicts correlate significantly with MZ-difference scores on $\mathrm{P}$, $r(46)=.30, p=.04, r^{2}=.09$.

Cross-twin, cross-dimension correlations $\left(_{\text {cross }} r\right)$ are presented in Table 4. Such correlations provide information on whether phenotypic correlations may be genetically mediated. Warmth and Conflicts were related to $\mathrm{P}$. The pattern of ${ }_{\text {cross }} r$ s suggests that the relationships are partly due to nonadditive genetic factors.
Table 4. Cross-twin, cross-dimension and cross-sibling, cross-dimension correlations (cross $r$ ) between the FSPE environmental factors and J-EPQ personality factors

\begin{tabular}{lrrrr}
\hline Phenotypically correlated variables & cross $^{2}$ MZ & cross $^{r}$ DZ & cross ${ }_{\text {FS }}$ & cross ${ }_{\mathrm{HS}}$ \\
\hline FSPE2-P & $.384 * *$ & .134 & .009 & .226 \\
\hline FSPE1-P & $-.428 * * *$ & -.131 & -.003 & .246 \\
\hline P-L & $-.538 * * *$ & .022 & -.039 & .116 \\
\hline FSPE1-Warmth-FSPE2-Conflicts & $-.329 *$ & -.099 & -.070 & .083 \\
\hline E-N & $-.310 * *$ & $-.265 *$ & -.039 & -.054 \\
\hline FSPE2-E & .186 & -.002 & .060 & $.343 *$ \\
\hline FSPE1-E & .115 & .128 & .087 & -.075 \\
\hline FSPE1-N & -.001 & -.017 & .009 & .098 \\
\hline FSPE2-N & -.062 & .115 & .016 & .189 \\
\hline E-L & -.120 & -.026 & -.040 & -.127 \\
\hline N-L & -.133 & -.167 & -.94 & .020 \\
\hline P-N & .028 & .135 & .124 & .112 \\
\hline
\end{tabular}

Note: Correlations that indicate $\mathrm{Gm}$ are placed at the top of the table. E, extraversion; N, neuroticism; P, psychoticism/antisocial personality; L, lie/social desirability; FSPE1-Warmth, Warmth, support and openness from parents, siblings and peers; FSPE2-Conflicts, Family conflicts and school discipline.

${ }^{\star} p \leq .05,{ }^{\star \star} p \leq .01,{ }^{\star \star \star} p \leq .001$.

The correlation between $\mathrm{P}$ and $\mathrm{L}$ showed the same pattern. The negative relationship between Warmth and Conflicts showed some $\mathrm{Gm}$ as well, likely due to $r \mathrm{GE}$, a response to genetically influenced personality. Other phenotypic correlations appear to be mainly mediated by nonshared environment (measurement errors included).

\section{Discussion}

The goal of the present study was to reveal a potential $r \mathrm{GE}$ related to the FSPE environmental factors Warmth and Conflicts. The results show that both factors may be related to genetic factors, suggesting some reactive/evocative $r \mathrm{GE}$, that is, Warmth and Conflicts at home and in school may be a response to genetically influenced personality factors.

Warmth is also related to shared environment, and a large part of the variance in Conflicts is related to nonshared environment. These findings are in line with meta-analysis (Avinun \& Knafo's, 2014; Kendler \& Baker, 2007). The results for Conflicts is, however, not as clear as for Warmth. Signs of both additive and nonadditive 
genetic variance are present, but signs of shared environment are also seen. An unexpected high correlation for HSs was found. The sample size of HSs $(n<30)$ may explain such an odd outcome, but a significant correlation was also found for FSs, though this correlation was substantially lower. However, the cross-twin, cross-dimension correlation between Conflicts and P indirectly supports a nonadditive genetic hypothesis, as $\mathrm{P}$ showed a nonadditive genetic effect.

The personality factors $\mathrm{P}, \mathrm{L}$ and $\mathrm{E}$ showed heritability. The findings of a nonadditive genetic influence on $\mathrm{P}$ have also been found in other studies (Eaves et al., 1999; Hur, 2007; Tambs et al, 1991). P correlates strongly with Hostility (Knust \& Stewart, 2002), and this factor may also be influenced by nonadditive genetic factors (Hur, 2006). Further, P correlates negatively with Agreeableness (Big Five), and a nonadditive genetic effect has been found for this variable as well (Hahn et al., 2012). In comparisons with other traits, $\mathrm{P}$ possesses the highest effect-size value accounting for antisocial behavior (Heaven et al., 2004; Miller \& Lynam, 2001). Also, antisocial behavior assessed with questionnaires and observational methods yielded a high heritability of .67 (O'Connor et al., 1998). Genetic factors seem to be a complex source of variance in the development of antisocial personality/behavior, as genes may interact both within and between loci.

$\mathrm{N}$ showed the lowest heritability coefficient. For this trait, shared and nonshared environment were substantial. Classical twin studies have shown moderate heritability (Vukasovic \& Bratko, 2015), but in a twin-adoption study, heritability was .13 when correlated shared environment was taken into account (Pedersen et al., 1988), and the effect of shared environment was found to significantly reduce heritability for $\mathrm{N}$ alone among 32 traits (Felson, 2014).

A phenotypic correlation between $\mathrm{P}$ and Conflicts was found (.40). When the effects of age, sex, N, L, Warmth and number of siblings were removed, the partial correlation decreased to $.235(p<.001)$; thus, the variables share $5.5 \%$ of the variance. Cross-twin, cross-dimension correlation $\left({ }_{\text {cross }} r\right)$ provides further information about the origin of the relationship. A substantially higher ${ }_{\text {cross }} r$ for MZ twins than for DZ, FS and HS suggests nonadditive genetic variance as a mediating factor. The relationships between P-Warmth, P-L and Warmth-Conflicts showed the same nonadditive variance pattern. For half of the phenotypic correlations, nonshared environment and measurement error seem to be the main source of mediating factors, as the cross $r$ are close to zero in all four groups.

The EEA implies that shared environmental influences are equally important for MZ and DZ twins. That is, shared environment does not make MZ twins more similar phenotypically than DZ twins. The validation of EEA has been examined in many studies (Carbonneau et al., 2002; Derks et.al., 2006; Eaves et al., 2003; Felson, 2014; Pedersen et al., 1991). In conclusion, the findings show some degree of violation, but this does not alter the main conclusion about the importance of genetic factors. The most convincing evidence that the EEA is neither fully valid nor completely erroneous comes from twin-adoption studies. Correlations for $\mathrm{MZ}$ and DZ twins reared together are significantly higher than for $M Z$ and $D Z$ twins reared apart, and these differences are more pronounced for $\mathrm{MZ}$ twins reared apart than for $\mathrm{DZ}$ twins reared apart, suggesting an assimilation effect for $\mathrm{MZ}$ twins. Nevertheless, heritability estimates based on twins reared apart, where the EEA has less meaning, are significant for both personality (Pedersen et al., 1988; Plomin et al., 1998; Vukasovic \& Bratko, 2015) and family environmental measures (Plomin et al., 1988).
The pattern of cross-twin, cross-dimension correlations in the present study does not support a common shared environment hypothesis as an important mediating factor. However, a special MZ twin-specific shared environmental effect cannot be ruled out for $\mathrm{P}$ and $\mathrm{L}$. The mean and variance for $\mathrm{P}$ was significantly lower for MZ than for FS and HS. On L, MZ differed from FS, but not from DZ and HS. Keller et al. (2005) have found a special twin environmental effect, accounting for $4 \%-11 \%$ of the phenotypic variance on $\mathrm{P}$ and $\mathrm{L}$. Taking this factor into account, the heritability for P and L may be somewhat overestimated. Such a downward adjustment does not alter the impression that nonadditive genetic variance seems to be an important factor for $\mathrm{P}$ and L. Broad-sense heritability includes both additive and nonadditive genetic variance, and because the present twin sample is not large, the relative importance of these sources of genetic variance cannot be specified.

To increase power, the full sample of same- and opposite-sex DZ, FS and HS pairs was used. MZ twins are always of the same sex. If sex differences are substantial and genetically determined, the heritability estimates may be biased. However, none of the intraclass correlations and cross-twin, cross-dimension correlations in the full samples differed significantly from the smaller samples of same-sex pairs, nor did the correlations differ when the effect of sex was removed in a partial correlation analysis. Large studies have shown that sex differences are quite small and that genetic and shared environmental effects on these differences are also small, because the same genes seem to influence most of the phenotypes in men and women (Stinger et al., 2017; Vink et al., 2012).

HSs were surprisingly difficult to find. The goal was to recruit $30-100$ pairs, but only 25 pairs responded to the inquiry. The reason for this is speculative. According to Statistics Sweden, the number of HSs in the population of 10- to 20-year olds has decreased during the 2000s. Of all children born in 2011, $15 \%$ had a HS at birth (Statistics Sweden, 2013). If the presence of HSs decreases in society, some stigmatization effect may occur, making HSs (or their parents) less prone to participate in studies that emphasize this type of kinship.

The information of zygosity and sibling type was delivered by the parents. Using the DNA markers/blood typing method, studies have shown that parents' accuracy in determining zygosity is between $80 \%$ and $85 \%$. These figures are lower compared to zygosity determination by questionnaires (90\%-93\%; Rietveld et al., 2000; Ooki et al., 1990; van Jaarsveld et al., 2012). DZ twins are sometimes misclassified as MZ twins (17\%-26\%), and DZ twins are misclassified as MZ twins (0.5\%-2\%; Herle et al., 2016; King et al., 1980). If the results in the present study are biased by the method of zygosity determination, MZ twins would probably not be more similar than DZ twins on five out of six variables.

The response rate was somewhat over $14 \%$. This may be a problem if the respondents differ substantially from the nonresponders in some way. However, the mean differences between the sample in this study $(N=506)$ and the samples in the J-EPQ and FSPE-manuals $(N=1090+245)$ were small according to Cohen's $d$ (0.12-0.45). Coccaro and Jacobsen (2006) showed that a response rate of only $12 \%$ of a twin population was sufficient. The respondents did not differ from the nonresponders in any meaningful respect.

The relationships between parental rejection, low parental warmth and antisocial-related personality has been documented in studies with various designs, such as studies using a retrospective approach (Kraft \& Zuckerman, 1999), current rating approach 
(Nishikawa et al., 2010; Persson, 2014), observational MZ twindifference approach (Deater-Deckard et al., 2001; Pike et al., 1996) and crosscultural studies as well as in meta-analyses (Khalegue \& Rohner, 2011; Lila et al., 2007). The findings in the present study highlight the complexity in such relationships, that is, genetic mediating factors (including nonadditive genetic variance), $r \mathrm{GE}$, specific shared $\mathrm{MZ}$ twin environments and nonshared environments, may all contribute to antisocial personality as captured by the P-scale in J-EPQ.

Acknowledgments. I would like to thank the 506 children who participated in the study and their parents for their help with test administration in the home. I would also thank Professor Martin Bäckström, head of the Division of Personality and Social Psychology at the Department of Psychology, Lund University, for his valuable comments on the manuscript.

Financial Support. I would like to thank Per Johnsson, $\mathrm{PhD}$, former head of the Department of Psychology, Lund University, for the research grant that covered the costs paid to the SPAR for the recruitment of participants.

Conflict of Interest. None.

\section{References}

Avinun, R., \& Knafo, R. (2014). Parenting as a reaction evoked by children's genotype: A meta-analysis of children-as-twins studies. Personality and Social Psychology, 18, 87-102.

Ayoub, M., Briley, D. A., Grotzinger, A., Patterson, M. W., Engelhardt, L. E., Tackett, J., .. Tucker-Drob, E. M. (2019). Genetic and environmental associations between child personality and parenting. Social Psychology and Personality Science, 10, 711-721.

Brajsa-Zganec, A., Ivanovic, D., \& Lipovcan, L. K. (2011). Personality traits and social desirability as predictors of subjective well-being. Psihologijske Teme, 2, 261-276.

Carbonneau, R., Rutter, M., Silberg, J. L., Simonoff, E., \& Eaves, L. J. (2002). Assessment of genetic and environmental influences on differential ratings of within-family experiences and relationships in twins. Psychological Medicine, 32, 729-741.

Chapman, J. P., Chapman, L. J., \& Kwapil, T. R. (1993). Does the Eysenck Psychoticism scale predict psychosis? A ten-year longitudinal study. Personality and Individual Differences, 17, 369-375.

Cheverud, J. M., \& Routman, E. J. (1996). Epistasis as a source of increased additive genetic variance at population bottlenecks. Evolution, 50, 1042-1051.

Chipuer, H. M., Plomin, R., Pedersen, N. L., McClearn, G. E., \& Nesselroade, J. R. (1993). Genetic influence on family environment: The role of personality. Developmental Psychology, 29, 110-118.

Coccaro, E. F., \& Jacobsen, K. C. (2006). PennTwins: A population-based cohort for twin studies. Twin Research and Human Genetics, 9, 998-1005.

Colledani, D., Anselmi, P., \& Robusto, E. (2018). Using item response theory for the development of a new short form of the Eysenck Personality Questionnaire-Revised. Frontiers in Psychology, 9, 1-13.

Costa, P. T., Jr., \& McCrae, R. R. (1985). Comparison of EPI and psychoticism scales with measures of the five-factor model of personality. Personality and Individual Differences, 6, 583-597.

Deater-Deckard, K., Pike, A., Petrill, S. A, Cutting, A. L., Hughes, C., \& O'Connor, T. G. (2001). Non-shared environmental processes in socialemotional development: An observational study of identical twin differences in the preschool period. Developmental Science, 4, F1-F6.

Derks, E. M., Dolan, C. V., \& Boomsma, D. I. (2006). A test of the Equal Environment Assumption (EEA) in multivariate twin studies. Twin Research and Human Genetics, 9, 403-411.

Dobewall, D., Savelieva, K., Seppälä, I, Knafo-Noam, A., Hakulinen, C., Elovaino, M., \& Hintsanen, M. (2019). Gene-environment correlations in parental emotional warmth and intolerance: Genome-wide analysis over two generations of the Young Finns Study. Journal of Child Psychology and Psychiatry, 60, 277-285.
Eaves, L., Foley, D., \& Silberg, J. (2003). Has the 'Equal environments' assumption been tested in twin studies? Twin Research, 6, 486-489.

Eaves, L., Heath, A., Martin, N., Maes, H., Neale, M., Kendler, K., . . Corey, L. (1999). Comparing the biological and cultural inheritance of personality and social attitudes in the Virginia 30000 study of twins and their relatives. Twin Research, 2, 62-80.

Eysenck, H. J., \& Eysenck, S. B. G. (1976). Psychoticism as a dimension of personality. Hodder and Stoughton.

Eysenck, S. B. G., von Knorring, A.-L., \& von Knorring, L. (1988). A crosscultural study of personality: Swedish and English children. Scandinavian Journal of Psychology, 29, 152-161.

Falconer, D. S., \& Mackay, T. F. (1998). Introduction to quantitative genetics. Longman Group.

Felson, J. (2014). What can we learn from twin studies? A comprehensive evaluation of the equal environments assumption. Social Science Research, 43, 184-199.

Hahn, E., Spinath, F. M., Siedler, T., Wagner, G. G., Schupp, J., \& Kandler, C. (2012). The complexity of personality: Advantages of a genetically sensitive multi-group design. Behavior Genetics, 42, 221-233.

Heath, A. C., \& Martin, N. G. (1990). Psychoticism as a dimension of personality: A multivariate genetic test of Eysenck and Eysenck's psychoticism construct. Journal of Personality and Social Psychology, 58, 111-121.

Heaven, P. C. L., Newbury, K., \& Wilson, V. (2004). The Eysenck Psychoticism dimension and delinquent behaviours among non-criminals: Changes across the lifespan? Personality and Individual Differences, 36, 1817-1825.

Herle, M., Fildes, A., van Jaarsveld, C., \& Rijsdijk, F. (2016). Parental report of infant and child eating behaviors are not affected by their beliefs about their twins' zygosity. Behavior Genetics, 46, 763-771.

Hur, Y.-M. (2006). Nonadditive genetic effects on hostility on South Korean adolescent and young adult twins. Twin Research and Human Genetics, 9, 637-641.

Hur, Y.-M. (2007). Evidence for nonadditive genetic effects on Eysenck Personality Scale in South Korean twins. Twin Research and Human Genetics, 10, 373-378.

Jaffee, S. R., \& Price, T. S. (2007). Gene-environment correlations: A review of the evidence and implications for prevention of mental illness. Molecular Psychiatry, 12, 432-442.

Keller, M. C., Coventry, W. L., Heath, A. C., \& Martin, N. G. (2005). Widespread evidence for non-additive genetic variation in Cloninger's and Eysenck's Personality Dimensions using a twin plus sibling design. Behavior Genetics, 35, 707-721.

Kendler, K. S., \& Baker, J. H. (2007). Genetic influences on measures of the environment: A systematic review. Psychological Medicine, 37, 615-626.

Khalegue, A., \& Rohner, R. P. (2012). Transnational relations between perceived parental acceptance and personality dispositions of children and adults: A meta-analytic review. Personality and Social Psychology Review, $16,103-115$.

King, M-C., Friedman, G. D., Lattanzio, D., Rodgers, G., Lewis, A. M., Dupuy, M. E., \& Williams, H. (1980). Diagnosis of twin zygosity by selfassessment and genetic analysis. Acta Geneticae Medicae et Gemellologiae, 29, 121-126.

Klahr, A. M., Thomas, K. M., Hopwood, C. J., Klump, K. L., \& Burt, S. A. (2013). Evocative gene-environment correlation in the mother-child relationship: A twin study of interpersonal processes. Developmental Psychopathology, 25, 105-118.

Knust, S., \& Stewart, A. L. (2002). Risk-taking behavioue and criminal offending: An investigation of sensation seeking and the Eysenck Personality Questionnaire. International Journal of Offender Therapy and Comparative Criminology, 46, 586-602.

Kraft, M. R., \& Zuckerman, M. (1999). Parental behavior and attitudes of their parents reported by young adults from intact and stepparent families and relationships between perceived parenting and personality. Personality and Individual Differences, 27, 453-476.

Lila, M., Garcia, F., \& Garcia, E. (2007). Perceived paternal and maternal acceptance and children's outcome in Colombia. Social Behavior and Personality, 35, 115-124. 
Loehlin, J. C. (1972). An analysis of alcohol-related questionnaire items from the national merit twin study. Annals of the New York Academy of Science, 197, 117-120.

Miller, J. D., \& Lynam, D. (2001). Structural models of personality and their relation to antisocial behavior: A meta-analytic review. Criminology, 39, 765-798.

Nishikawa, S., Sundbom, E., \& Hägglöf, B. (2010). Influence of perceived parental rearing on adolescent self-concept and internalizing and externalizing problems in Japan. Journal of Child and Family Studies, 19, 57-66.

O’Connor, T. G., Neiderhiser, J. M., Reiss, D., Hetherington, E. M., \& Plomin, R. (1998). Genetic contribution to continuity, change, and co-occurrence of antisocial and depressive symptoms in adolescence. Journal of Child Psychology and Psychiatry, 39, 323-336.

Ones, D. S., Viswesvaran, C., \& Reiss, A. D. (1996). Role of social desirability in personality testing for personnel selection: The red herring. Journal of Applied Psychology, 81, 660-679.

Ooki, S., Yamada, K., Asaka, A., \& Hayakawa, K. (1990). Zygosity diagnosis of twins by questionaire. Acta Geneticae Medicae et Gemellologiae, 39, 109-115.

Pedersen, N. L., McClearn, G. E., Plomin, R., Nesselroade, J. R., Berg, S., \& DeFaire, U. (1991). The Swedish adoption twin study of aging: An update. Acta Geneticae Medicae et Gemellologiae, 40, 7-20.

Pedersen, N. L., Plomin, R., McClearn, G. E., \& Friberg, L. (1988). Neuroticism, extraversion, and related traits in adult twins reared apart and reared together. Journal of Personality and Social Psychology, 55, 950-957.

Persson, N. B. G. (1997). Growth environment and personality in adult migraineurs and their migraine-free siblings. Headache, 37, 159-168.

Persson, N. B. G. (2011). Family and School Psychosocial Environment (FSPE): Development of a brief questionnaire measuring perceived psychosocial environments in children/siblings. Scandinavian Journal of Psychology, 52, 303-307.

Persson, N. B. G. (2014). A study of personality and family and school environment and possible interactional effects in 244 Swedish children A multiple regression analysis. Psychology, 5, 886-895.

Pike, A., McGuire, S., Hetherington, E. M., Reiss, D., \& Plomin, R. (1996). Family environment and adolescent depression and antisocial behavior: A multivariate genetic analysis. Developmental Psychology, 32, 590-603.

Plomin, R. (2014). Genotype-environment correlation in the era of DNA. Behavioral Genetics, 44, 629-638.

Plomin, R., Corley, R., Caspi, A., Fulker, D. W., \& DeFries, J. (1998). Adoption results for self-reported personality: Evidence for nonadditive genetic effects? Journal of Personality and Social Psychology, 75, 211-218.
Plomin, R., Pedersen, N. L., Nesselroade, J. R., \& Bergeman, C. S. (1988). Genetic influences on childhood family environment perceived retrospectively from the last half of the life span. Developmental Psychology, 24, $738-745$.

Rietveld, K. J. H., van der Valk, J. C., Bongers, I. L., Stroet, T. M., Slagboom, P. E., \& Boomsma, D. I. (2000). Zygosity diagnosis in young twin by parental report. Twin Research, 3, 134-141.

Roy, A. (2012). The short-form of the revised junior Eysenck Personality Questionnaire: A Bengali edition. Industrial Psychiatry Journal, 21, $115-118$.

Sarzynska, J., Falkiewicz, M., Riegel, M., Babula, J., Margulies, D. S., \& Szatkowska, I. (2017). More intelligent extraverts are more likely to deceive. PLOS One, 12, 1-17.

Statistics Sweden. (2019). Total fertility rate by region and sex. Year 2000-2019. http://www.statistikdatabasen.scb.se/pxweb/sv/ssd/START_BE_BE0101_ BE0101H/FruktsamhetSum/

Statistics Sweden. (2013). Having children in new relationships. https://www. scb.se/contentassets/47a41f2180784353a737c6d03433aac6/be0701_2013a01_ br_be51br1302.pdf

Stinger, S., Polderman, T. J. C., \& Posthuma, D. (2017). Majority of human traits do not show evidence for sex-specific genetic and environmental effects. Scientific Reports, 7, 1-7.

Tambs, K., Sundet, J. M., Eaves, L., Hornberg Solaas, M., \& Berg, K. (1991). Pedigree analysis of Eysenck Personality Questionnaire (EPQ) scores in monozygotic (MZ) twin families. Behavior Genetics, 21, 369-382.

van Jaarsveld, C. H. M., Llewellyn, C. H., Fildes, A., Fisher, A., \& Wardle, J. (2012). Are my twins identical: Parents may be misinformed by prenatal scan observations. BJOG, 517-518.

Vernon, P. A., Jang, K. L., Harris, J. A., \& McCarty, J. M. (1997). Environmental predictors of personality differences: A twin and sibling study. Journal of Personality and Social Psychology, 72, 177-183.

Vink, J. M., Bartels, M., van Beijsterveldt, T. C. E. M., van Dongen, J., van Beek, J. H. D. A., Distel, M. A., \& Boomsma, D. I. (2012). Sex differences in genetic architecture of complex phenotypes? PLOS ONE, 7, 1-8.

Vinkhuyzen, A. A. E., van der Sluis, S., de Geus, E. J. C., Boomsma, D. I., \& Posthuma, D. (2010). Genetic influences on 'environmental' factors. Genes, Brain and Behavior, 9, 276-287.

Vukasovic, T., \& Bratko, D. (2015). Heritability of personality: A meta-analysis of behavior genetic studies. Psychological Bulletin, 141, 769-785.

Wakefield, J. C. (1997). Diagnosing DSM-IV-Part II: Eysenck (1986) and the essentialist fallacy. Behaviour Research and Therapy, 35, 651-665. 